\title{
Assessment of Writing Skills in English Language among Students of the Walled City Schools at the Elementary Level
}

\author{
Naima Urooj \\ (Department of Educational Studies, Jamia Millia Islamia, New Delhi, India)
}

\begin{abstract}
Researches in learning of English as second language has seen many innovations in terms of development of the five skills of language learning, namely, Listening, Speaking, Reading, Writing and Thinking. It is only after sufficient development of the first three, that proficiency in the last two skills of language learning can be achieved. If not in sequence, then at least simultaneously. In a revolutionary step, with regard to English language, the Government of Delhi in April 2000 introduced English as a second language from Class I in all of its schools. To implement its decision effectively, the government delved into the task of developing English textbooks and training its teachers on language content and pedagogy accordingly. The present study seeks to understand and assess the performance of VIII standard government school students in English language, post this decision. For this purpose, focus of the study was on assessment of writing skills among students of Class VIII studying in three government schools of the walled city area of Delhi. A Language proficiency test was developed and administered among the students to understand the proficiency attained in English.
\end{abstract}

Keywords: English as second language, Elementary education, Language proficiency tests, Writing skill

\section{INTRODUCTION}

Amongst the four skills of language learning, namely Listening, Speaking, Reading and Writing, writing skill has come to take precedence over others. The reason could be attributed to the education system which we have India, which requires students to express themselves mostly in writing. The other possible reason could be the very nature of Writing as a skill which is active rather than passive.

One of the questions pertaining to the development of writing skill among those students who are from ESL background is as to whether the focus should be exclusively on the said skill or some kind of exposure needs to be given to listening, speaking and reading skill before switching over to writing skill. Nowadays we also talk of a fifth skill of language learning, which is thinking skill. Another question that needs to be answered through some research is as to whether grammar plays any important role in developing students' writing skill. Hence, the subsequent question arises as to whether grammar needs to be taught as a separate subject or in an integrated manner. Also, if grammar is required for accuracy, what type of grammatical awareness need be given to the students so that without taking recourse to the traditional rules and regulations of grammar they can still feel comfortable in expressing their ideas both in speech and in writing. Apart from this, the place of the mother tongue in ESL also opens debate as to whether mother tongue should be treated as a barrier or as a strategy for the development of language skills amongst the students. These are all questions of extreme relevance when it comes to language learning.

The question that the present study intends to undertake is how important is the last skill, i.e., Writing skill in language learning and how it can be measured most accurately.

\subsection{Background}

Language Acquisition is a difficult and a rather complex process. Various psychologists at various times have attempted to explain this phenomenon of language acquisition. [1] B. F. Skinner, who was a behaviourist, suggested in Verbal Behaviour (1957) that a child imitates the language of its parents or caretakers. He argued that language acquisition is like any kind of cognitive behavior - it is learnt by reinforcement and shaping. [2] Chomsky, who was a linguist, on the other hand argued that the ability of language acquisition was innate (1959). Children automatically acquire language by being exposed to it. This ability is supported by what Chomsky calls a LAD (innate language acquisition device) an inbuilt mechanism that automatically allows a child to decode any spoken language it hears around it. Interactionists such as [3] Jerome Bruner (1983) suggested that the language behaviour of adults when talking to children is specially adapted to support the acquisition process. This support is often described to as scaffolding for the child's language learning. Bruner also coined the term Language Acquisition Support System or LASS in response to Chomsky's LAD. 
There are a number of factors which affect the process of language acquisition, ranging from the method of teaching adopted by the teacher to the socio-economic background of the learners, their age, motivation level, environment of their school and so on. The basic aim of teaching is development of communicative competence among learners. [4] Chomsky (1965) in 'Aspects of the Theory of Syntax' defines competence as the perfect knowledge of an ideal speaker-listener of the language in a homogeneous speech community. Communicative Competence is thus the ability of the learner to express his thoughts, feelings, ideas and opinions in the best possible manner, his understanding and correct interpretation of the speech and writing of others, his efficient participation in a spoken or written discourse involving two or more persons, his general understanding of the language and the most appropriate use of it [5] (Mukherjee, 2007, p9).

\subsection{Writing in ESL Classrooms}

According to [6] Thirumalai (2002), writing is an individual effort. Individuals compose their thoughts often in privacy and then reduce their thoughts to writing, using the strict conventions followed in the language. The acquisition of writing is a step further and the learner must now transfer the symbolization he/she acquired in the process of speech acquisition to written language. "Writing is more an individual effort than speaking, while at the same time more rule-bound and therefore more error-prone. . . The speaker does not have to pronounce each word exactly according to one standard of pronunciation or one model of structure, while the writer is expected to produce according to one model of spelling, and usually a reduced range of structures, with 100 percent accuracy" [7] (Bowen et al. 1985). Everyone will agree with Bowen et al (1985) when they declare that "writing is more rule-bound than speaking. Considering the control of the orthographic system, the careful organization, and the linguistic conservatism required, writing is the most demanding of the language skills."

[6] Thirumalai (2002) asserts that the writing classes have the potential to help consolidate and improve the students' speaking and reading skills. However, it is important for teachers to remember that writing is an important skill which can be taught as an end in itself, although none of the language skills is far removed from the other language skills. Focusing on writing as an independent skill helps teachers to identify the specific problems faced by the learners, and to identify the specific needs of the learners relating to writing. Mechanics of writing are distinct from the mechanics of other skills such as speaking and reading. While reading involves seeing and pronouncing, writing involves association of sounds with mental composition of thoughts and their orderly presentation, and hand movements.

\subsection{Need of the Study}

English is quite often described as global lingua franca as it is the major communication tool for science events, business, aviation, entertainment and diplomacy. In the light of this background, 'Teaching of English' takes an important place in the school curriculum. Various commissions and committees over the years have given significant thought to the place and importance of English language. However, the status of English became well-defined with the proposal of The Three Language Formula by [8] Indian Education Commission (1964-66), which recognized English as "an associate official language of the Indian Union."

A revolutionary step, with regard to English language, came in with the decision of Government of Delhi to introduce English as a second language from Class I in all its schools from April, 2000. To implement its decision effectively, the government delved into the task of developing English textbooks and training its teachers on language content and pedagogy accordingly. As it is often said, English should be taught keeping in view the communicative needs of the learners, it should enable them to learn, to understand, to speak, to read and to write the English language. For such a task, we need not only comprehensive textbooks but also motivated and skilled teachers who are competent to develop the communicative competence of the students through various tasks and activities revolving around the syllabus.

\section{DESIGN OF THE STUDY}

Keeping in view the aims of English language learning, the present study intended to test only one performing skill, that is, Writing, of the four English language skills, namely, Listening-Speaking-ReadingWriting, of Class VIII students studying in the walled city schools of Delhi. Significantly, the purpose of selecting Class VIII of the three government schools was to study the performance in English language of the students who have been familiar with the language since Class I. The schools selected are all girls', all boys' and co-ed each, the purpose of which is to give an insight into the factors that affect differential achievement within the schools. It will help judge gender differences in terms of language learning. The present study also enquires into the difference between the expected learning outcomes as stated by NCERT and the students' achievement of them in terms of language skills. Class VIII English NCERT textbook 'Honeydew' talks of the learning outcomes and gives guidelines for the same in its 'Notes for the Teachers' printed at the beginning of the book. It talks of "continuous exposure to the language in meaning-focused situations", "interactions", "discussions" and "sharing of ideas" by the learners in order to enable them to converse confidently and effectively in the 
language. For writing skills, the textbook provides for developing them by encouraging the learners to "compose poems", write new words with meanings and short stories. All such activities aim at the enhancement of the writing of the learners, which is an important means of reflection, of learning as well as a mode of communication.

\subsection{Objectives}

- To study whether they are able to express their thoughts, ideas and feelings in different forms of writing.

- To find out the relationship between the expected learning outcomes and the achievement of the students in acquisition of language skills.

- To study the factors affecting differential achievement within the sampled schools.

\subsection{Sample}

The data for the present study has been collected from three schools - all girls', all boys' and co-ed each - located in the walled city of Delhi. One section of Class VIII of all the three schools was tested on writing skills. The sample consists of 30 students of all boys' school, 30 of all girls' school and 24 students of the co-ed school located in Old Delhi area of Delhi, making it a total of 84 students. The purpose of selecting all boys', all girls' and co-ed each was to give an insight into the factors that affect differential achievement within the schools. It will help judge gender differences in terms of language learning.

Keeping in mind the restrictions of time, convenience sampling technique was utilized. The schools were selected depending upon their location. Since the study aims at testing the writing skills of the students studying in the government schools falling in the walled city of Delhi, all three schools were selected accordingly. The selection of schools also depended upon the granting of permission by the Principal of the respective school. The researcher was denied permission in several schools as the heads of those schools felt that it would upset the school schedule and waste the time of the teachers.

\subsection{Tools}

For the present study, the investigator prepared a Language Proficiency Test for assessing the Writing skill of the Class VIII students. For the preparation of this test, the investigator consulted an expert of English Language Teaching (ELT).

The test constructed by the investigator consists of six (6) questions. Each question framed is related to the proficiency in writing that should have been developed in Class VIII students of government schools as per the learning outcomes given by NCERT in its textbook 'Honeydew'. The questions aim at testing:

- correct grammar usage,

- correctly structured sentences,

- good knowledge of vocabulary as well as of proverbs, idioms etc.

- awareness of the learners in writing of both formal as well as informal letters, writing of paragraphs with the help of visual and verbal clues, use of idioms, dialogues from a story and a story from dialogue, and so on with correct sequence of ideas and logical representation of it.

\subsection{Procedure of Data Collection}

The investigator visited the three government schools in the Old Delhi area for at least five times and up to a maximum of ten visits. A preliminary visit was made for seeking permission from the Principals of the respective schools. Once the sample of students, i.e. one section of Class VIII from each school, was selected the researcher noted down the time-table of the class. Before the administration of the test the researcher, for own benefit, observed a few classes to know about the method/s of teaching adopted by the teachers. The other purpose of observing the classroom teaching informally was to build a rapport with the teacher as well as the students which would help later in the administration of the test.

\subsubsection{Administration of the test}

The test was administered by the researcher after fixing time with the teacher. The researcher asked for one hour for conducting the test, which the teacher readily agreed for. After giving out the test papers to the students, the researcher read the paper first in English and explained what was to be done in each question in Hindi, for the benefit of the students. The students were then asked to begin with the test. At the close of one hour, the students were given extra time of about 20 minutes, since most of them were unable to finish the paper in time. The administration of the test took place in the absence of the school teacher in all the three schools selected. 


\subsection{Analysis of the Data}

The data collected was analyzed quantitatively and qualitatively. The first step in analyzing data qualitatively is to organize the data. Once the data is organized, the researcher can move on to the next stage of description. The researcher describes the pertinent aspects of the study like the setting, the individuals being studied, their viewpoints and effects of the activities on the participants. Consequently, the researcher begins the critical phase of interpretation [9] (Best and Kahn, 1993).

\section{DISCUSSION}

In the present study, a language proficiency test was built and used for the purpose of data collection. The test constructed consists of six questions or tasks. Each of the six questions aims at fulfilling one or the other characteristics defining a good piece of writing.

\section{Task 1}

The first task in the test was related to a visual. This task was a series of five pictures that tell the story of two donkeys. The students were asked to look at the visuals, describe the events happening in each of the pictures and develop the story in their own words. This was done not only to test the student's imaginative faculty but also their ability to express their thoughts in writing.

\section{Task 2}

The second task or question given was that of letter writing. The students were asked to write a letter to their Principal suggesting for improvements in their school. A few options were also provided in the question itself for assistance like suggesting for a big spacious building, good and open playground, clean toilets, water and electricity supply, and well-equipped laboratories and library. The task was meant to assess their ability to communicate to their higher-ups in the target language. The task of letter-writing also helps the students distinguish between formal and informal letters and how in these two types of letters both the format and the style of writing change.

Task 3

As the words need to be taught not in isolation but in a given context, it entirely depends upon the teacher whether he/she teaches all the three words of an idiom, i.e. 'slow and steady', separately or in a given context. Students' writing ability always improves when words are taught in meaningful context. In the present study, the task of idioms was given to assess the ability of the students to form sentences describing a meaningful situation.

Task 4

The fourth task of that of unseen passage was given to test the students' understanding of the text. The task also aimed at testing the ability of the students to respond to the questions asked in writing. Apart from this, ability of the students to deduce the meaning of the new lexical items used in the text was also tested.

\section{Task 5}

This task was given to the sampled students to assess their writing ability with reference to using a flow chart for making tea. This exercise helped the investigator to know whether the students were able to use sentences in logical consistency or not, with coherence and conciseness.

\section{Task 6}

This last and final task was used to test students' writing ability in both active and passive voices. This was essentially needed as without having proper grounding in the two voices, a student may be unable to express his/her ideas comfortably.

\section{OBJECTIVE WISE DISCUSSION}

The $1^{\text {st }}$ Objective of the study was to study whether the students are able to express their thoughts, ideas and feelings in different forms of writing. Following the analysis of the data collected, it can be concluded that a very small percentage of students were able to complete the test proficiently. In the first task, merely $29.8 \%$ of the students were able to perform well in it. Though the students did show their imagination by developing a story based on the visuals, majority of the students were unable to express themselves in the target language. The only probable reason can be their lack of proficiency in the target language. Coming to the second task a similar problem in expression of thoughts in the target language was observed. Though most of the students have knowledge of letter writing, they were unable to write proficiently. $56.4 \%$ of the students showed some ability in letter writing. Here it would be crucial to mention that some students wrote letter which was not related to the question. It shows that perhaps the teachers use the method of rote-memorization in the teaching of the target language. 
Task 3 involved making sentences of idioms. Knowledge of proverbs, idioms, etc. are some of the characteristics of good writing which the students in general were unable to display. Similar was the case with task 5 and 6, which involved knowledge of grammatical structures and logical consistency in writing. An average of $34.5 \%$ and $31.3 \%$ of students were able to show some knowledge of it. The probable reason behind this could be that teachers give no importance to grammar and sentence structures while teaching the target language. In task 4 , the performance of students was above average, with $66.5 \%$. But the task was mainly to check the comprehension of students and did not involve much of written expression in the target language. However, it shows that students were able to understand the content of the passage and answer correctly in the target language with a little bit of imitation of the language from the passage.

The $2^{\text {nd }}$ Objective of the study was to find out the relationship between the expected learning outcomes and the achievement of the students in acquisition of language skills. In the document, [10] 'Quality Indicators in English for Class VIII' the expected learning outcomes have been given. It gives a description of skills and achievements that the learners of English should have developed at the end of Class VIII. According to this document, a good piece of writing must consist of correct grammar usage, correctly structured sentences, good knowledge of vocabulary as well as of proverbs, idioms etc. The learners must be aware of the mechanics of writing and make correct use of it. It further goes on to describe the kind of writing that the learners must have awareness of. For instance, writing of both formal as well as informal letters, writing of paragraphs with the help of visual and verbal clues, writing of brief reports, maintaining records, writing notices for the school notice board, dialogues from a story and a story from dialogue, stories from their own imagination, poems, jokes, riddles, slogans and so on with correct sequence of ideas and logical representation of it. The test constructed by the researcher was largely based on the description of language skills, with special reference to writing, given in this document. As said earlier, the data shows that most of the students are not proficient in the target language and majority of them were unsuccessful in completing the test skillfully. In task 1, based on visuals only $29.8 \%$ of the students were able to perform. Amongst these too the written expression in terms of grammar usage, correctly structured sentences, vocabulary etc. was not up to the mark.

In letter writing, though the students did show awareness of the format, their written expression was again very poor. Some of the students had written pre-memorized letter which was not even related to the topic given. A general lack of sequencing of ideas and logical consistency was also seen. In the task where the students were asked to write meaningful sentences using idioms, it was found that students lacked the knowledge of idioms. Only $6.1 \%$ of the students (combined) were able to make sentences using the idioms. The remaining 93.9\% couldn't even attempt the question as they had no understanding of it. In an informal interaction with students, the investigator found out that most of them didn't even know the meaning of the word 'idioms'. The fourth task was given mainly to assess the comprehension of the students and whether they were able to reproduce this knowledge in the questions that followed the passage. $66.5 \%$ of the students were able to perform this task with efficiency. It shows that the students do have basic understanding of the target language. The remaining two tasks, Task 5 and 6 were meant to assess the knowledge of grammar amongst the students and its usage. The students showed a general inability in terms of grammar, sentence structure and other dynamics that go into writing as only $30 \%-35 \%$ of the students were able to do the tasks. There are certain learning outcomes expected of the learners (as given in 'Quality Indicators in English for Class VIII') one of which is to have knowledge of grammar in the writing of the target language. The results show that majority of the students ( $65 \%-70 \%$ approx.) were lacking in understanding of the grammatical concepts and sentence structures. The $3^{\text {rd }}$ Objective of the study was to examine the factors affecting differential achievement within the sampled schools.

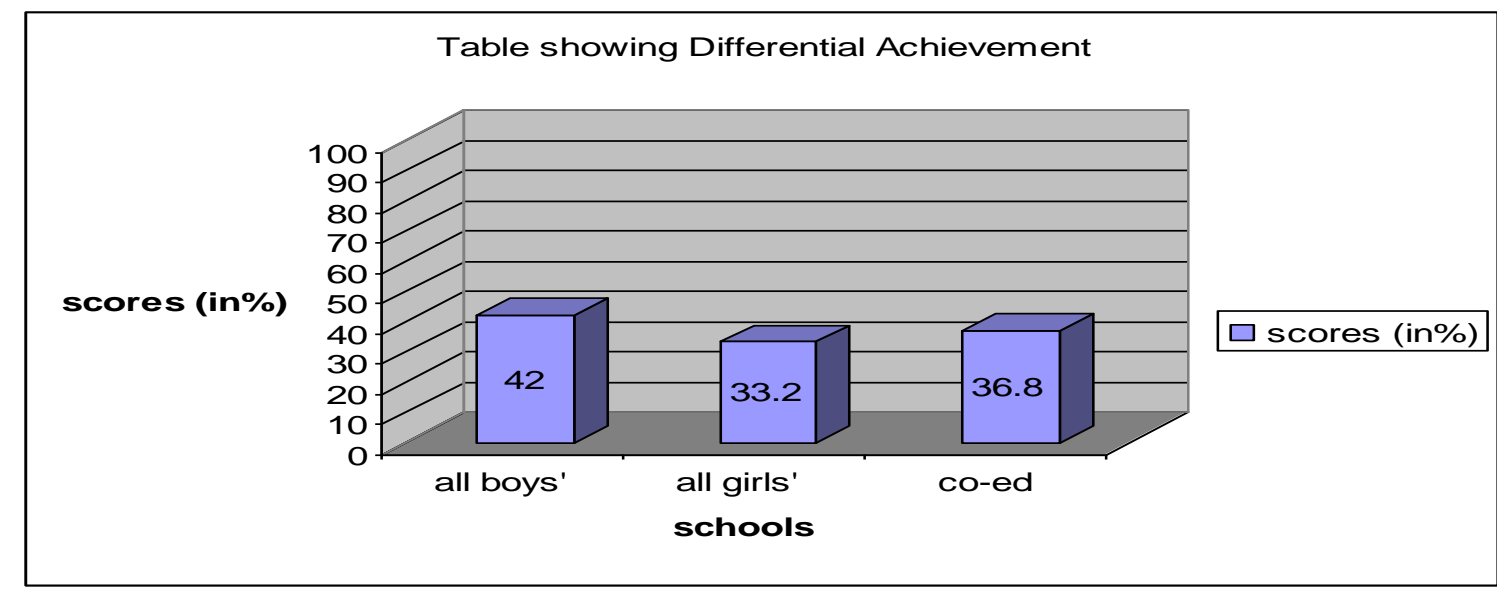

Graph 4A 
An item-wise analysis of the question gives an insight into the difference in achievement between girls and boys. Out of 6 questions, while the performance of the girls was superior the boys with $31 \%$ and $5.6 \%$ in the task 1 and 3 respectively, in the remaining 4 tasks the boys got ahead with a remarkable margin. In task 2, while $53.3 \%$ of the girls accomplished the task at hand proficiently, the percentage of boys was 59.3\%. Similar was the case with task 4,5 and 6 where $59.3 \%, 25 \%$ and $25.3 \%$ of the girls performed the task as compared to $76.6 \%, 45 \%$ and $40 \%$ of the boys respectively. Graph $4 \mathrm{~A}$ shows the overall performance of the three schools in the test. While only $33.2 \%$ of the students of all girls' school were able to perform well in the test, the percentage of students who were able to finish the test skillfully of all boys' school is 42 . An overall analysis shows that boys performed better at most tasks as compared to girls.

\subsection{Major findings}

- $\quad 31 \%$ of the students of all girls' school, $30 \%$ of the students of co-ed and $28.6 \%$ of all boys' school were able to develop a story based on the visuals provided.

- $59.3 \%$ of the students of all boys' school, $56.6 \%$ of the students of co-ed and $53.3 \%$ of the students of all girls' school showed their understanding of formal letter writing.

- Out of 100 , a mere $4.65 \%$ of students of all boys' school, $5.6 \%$ of all girls' and $8.3 \%$ of co-ed school were able to understand the meaning of the idioms given and make meaningful sentences of them.

- In the comprehension based task, the all boys' school performed the best with $76.6 \%$ of the students with correct answers while the other two schools, all girls' and co-ed weren't far behind with $53.9 \%$ and $63.5 \%$ respectively. Thus, by the results we can gather that students had a good understanding of the target language and could comprehend the task.

- $\quad 25 \%$ of the students of all girls' school, $33.5 \%$ of the students of co-ed and $45 \%$ of the students of all boys' school showed awareness of grammar and could develop a passage using the cues given for making tea.

- $\quad 40 \%$ of the students of all boys' school, $28.7 \%$ of the students of co-ed and $25.3 \%$ of the students of all girls' school managed to perform well in the last task which involved a change in voice from active to passive. Such low scores (in \%) show the minimal understanding of grammar and sentence construction amongst the students, which is essentially needed for high-quality expression in writing.

- With respect to differential achievement, $33.2 \%$ of the students of all girls' school were able to carry out the test, while the percentage of students who were able to finish the test adeptly of all boys' school is 42 .

- Correct grammar usage is a pre-requisite of a good piece of writing. The test papers of the students displayed a general lack of understanding of grammar and its usage. The sentences used were incorrectly structured and lacked logical consistency.

- Majority of the students showed little or no awareness of the mechanics of writing. Their written expression lacked correct placing of punctuation marks, capitalization of letters and correct spellings.

- As the results show, majority of the students had knowledge of the format of formal letter writing, but their written expression was observed to be extremely poor.

- Another important finding with respect to letter writing is that some of the students wrote pre-memorized letter which was not even related to the topic given.

- Out of 84, eight students wrote their answer-sheets in mother tongue (Hindi) instead of the target language despite repeated instructions by the investigator. It stands proof of their discomfort and unfamiliarity with the target language. They were unable to express themselves in the target language.

- In the process of observing the classroom teaching (informally), the researcher found out that the teachers of all three schools taught the target language through the mother tongue (Hindi). Therefore, it can be said that the exposure of the students in the target language is limited.

- During the administration of the test, each and every line was read out to the students, first in English and then in mother tongue, for their benefit. It was done following the model of teaching as adopted by the teachers of the three schools.

- The students being taught through mother tongue perhaps counts for the reason for their unfamiliarity with the target language.

- Lastly, the researcher found that the performance of the students was not as per the expected learning outcomes (as given in 'Quality Indicators in English for Class VIII'). The written expression of the students was found to be poorly developed.

\section{CONCLUSION}

There are a number of factors which affect the teaching learning process. Factors such as environment and family background, method of teaching adopted by the teacher, aims of learning, age of the learners, motivation level, and school infrastructure and environment all play a vital role in success of learning process. As said by Sir Philip Sydney, teaching is the end of all learning. A teacher's primary role is not only to enable 
the students to understand what he is intending to say or teach. Teaching-learning process is just like making sound by clapping. Without two hands, we cannot clap. Like that without a right teacher and the students, the teaching learning process is meaningless. Therefore, the role of teacher also becomes extremely crucial in learning.

In the process of teaching-learning, the teacher should try to understand the students first. A teacher must give due consideration to the background of the learners, the families that they are coming from and must aim at keeping the learners motivated. As discussed before, motivation plays a significant role in language learning. Maintaining a high level of motivation during a period of language learning is one of the best ways to make the whole process more successful. The investigator of the present study observed that this crucial factor of motivation was missing amongst the students of the three sampled schools. While observing the classroom situation, a general disinterest was seen amongst the learners. The teachers did nothing in particular to motivate the learners or boost their morale.

The students were not able to converse in the target language nor were they able to express themselves in writing as seen in the test results. This could perhaps be because of the faulty methodology adopted by the teachers. The teachers were seen teaching the target language through the mother tongue, which shows the limited exposure the students get of the target language. Too much of interference of the mother tongue is probably the reason for their incompetence in the target language. Another reason for the lack of proficiency in English could be attributed to skip gradient or the gap in the process of teaching learning. Sometimes a teacher may miss or skip steps that go in the process of teaching learning. There are four basic language skills, which every learner must master. These are (a) Listening, (b) Speaking (c) Reading and (d) Writing. Listening and Reading are passive skills whereas Speaking and Writing are active skills. A language learner starts with listening to the sounds of different words, then moves on to attempting to speak them. After speaking, comes reading. A good amount of practice in all the three skills leads to good writing, which comes last of all skills. Unless the learners are not proficient in the first three skills, they cannot attain expertise in the skill of writing.

The importance of teaching of grammar as a means of developing language skills especially of those who have been learning English as a second language has been established before in the study. Grammar is needed for good verbal as well as written expression. There are a few research scholars who argue that the teaching of grammar should be limited. Limited as it may be, it is nonetheless vital. The significance of grammar in the teaching of a language cannot be denied. Therefore, the teachers of language must aim at developing grammatical awareness amongst their students. Faulty method of teaching adopted by the teacher can lead to development of faulty knowledge or no knowledge amongst the learners.

\section{RECOMMENDATIONS}

Learning a new language can be a stressful event. Even the best-prepared teacher will encounter problems unconnected, on the surface, to grammar, sentence structure, and vocabulary. In their introduction to [11] Language Transfer in Language Learning, editors Susan Gass and Larry Selinker (1992) list various factors in learning a new language: "age . . . motivation, loyalty to a language, language aptitude, and attitude" (p. 4). Teachers cannot cancel out these factors, but they can, hopefully, lessen the uneasiness or fear felt by most language learning students. Teachers need to be alert to "transfers" and "borrowings" that students may make as they acquire the new language.

Many scholars and researchers believe that using mother tongue in teaching-learning process is beneficial in early years of a child. Though it is true that Bilingual approach in language teaching helps in its acquisition, but its use should be to a limited extent. While discussing the influence of first language over the second language, it is appropriate to mention what [12] Lado (1979) had said that "those elements that are similar to his native language will be simple for him and those elements that are different will be difficult."

Therefore, the teacher must adopt a methodology in the teaching of English as a second language which helps in developing fluency in the target language amongst its learners. While selecting the method of teaching the socio-economic background of the learners, their age and motivation level, the aims of teaching and other such factors must also be kept in mind.

For the development of the language skills in general and of writing skills in particular, the teacher can initiate creative tasks in the classroom so that students may always feel motivated in expressing their feelings, ideas and wonderful thoughts in different forms of writings. As oral drill precedes writing so teachers before asking the students to write a story or a poem should start a discussion in the class. This will help the students generate more ideas on the topic they wish to write on. Encouraging the students to read books other than school texts, dictation, developing stories from pictures, writing stories and poems are other such tasks which can help improve the written expression of the students. 


\section{REFERENCES}

[1] Skinner, B.F. (1957). Verbal Behaviour. Copley Publishing Group.

[2] Chomsky, N. (1959). Review of "verbal behaviour" (Skinner 1957), Language 35:26-58, 1959.

[3] Bruner, J. (1983) Child's Talk: Learning to Use Language, New York: Norton.

[4] Chomsky, Noam (1965). Aspects of the Theory of Syntax. Cambridge, Mass.: MIT Press.

[5] Mukherjee, S (2007). Communicative Perspectives on Teaching of English. Academic Excellence, Delhi.

[6] Thirumalai, M.S. (2002). An Introduction to TESOL. Language in India www.languageinindia.com Vol.2: April 2002.

[7] Bowen, J. Donald, H. M. and Hilferty, A. (1985). TESOL Techniques and Procedures. Boston: Heinle \& Heinle.

[8] The Indian Education Commission (1964-66).

[9] Best, J.W. \& Kahn, J.V. (1993). Research in Education. Prentice Hall; 7th edition (January 1993).

[10] NCERT Publications (2008); Class VIII English textbook, Honeydew and Quality Indicators in English

[11] Gass S. and Selinker L. (1992). Language Transfer in Language Learning. John Benjamins Publishing.

[12] Lado, R. (1979). Language Teaching: A Scientific Approach. Mcgraw Hill Inc., New York. 